\title{
Biochemical constituents in leaf of Carica papaya - ethnomedicinal plant of Kachchh region
}

\author{
Suhas J. Vyas ${ }^{1}$, Taslim T. Khatri ${ }^{1}$, Vijay R. Ram ${ }^{1, \star}$, Pragnesh N. Dave ${ }^{1}$, \\ Hitendra S. Joshi ${ }^{2}$ \\ ${ }^{1}$ Department of Chemistry, KSKV Kachchh University, Bhuj - 370 001, Gujarat, India \\ ${ }^{2}$ Department of Chemistry, Saurashtra University, Rajkot - 360 005, Rajkott, India \\ *E-mail address: ram_vijay1982@yahoo.co.in
}

\begin{abstract}
Carica papaya Linn. is one of the valuable plant used for various purposes in medicinal field. Leaves, fruit and seeds of the C. papaya are used as ethnomedicine. This work describes biochemical constituents of leaves of C. papaya. Fresh leaves samples of the plant were collected during the month of January, 2013 from different parts of Bhuj in Kachchh district (Gujarat), India. The purpose of the study was to evaluate the biochemical composition in leaves of $C$. papaya growing in the semi-arid region of Gujarat and based on the result to justify its importance in various treatments of diseases. The dried leaves were further analyzed for biochemical constituents like $\mathrm{Ca}^{2+}, \mathrm{Mg}^{2+}, \mathrm{Na}^{+}, \mathrm{K}^{+}, \mathrm{Cl}^{-}$and $\mathrm{Li}^{+}$. The results indicated that the leaf extract of C. papaya has high potentiality for curing number of diseases.
\end{abstract}

Keywords: Carica papaya; Kachchh region; minerals; medicinal importance

\section{INTRODUCTION}

Carica papaya Linn. is usually cultivated in tropical regions, its commonly called as papaya in this part of the world and it's from the family Caricaceae. The plants produces natural compounds (annonaceous acetogenins) in leaf bark and twig tissues that possess both highly anti-tumour and pesticidal properties (Ayoola \& Adeyeye, 2010).

Carica is the only genus in the family Caricacea. It belongs to group of plants known as Laticiferous plants. Papaya grows best in a well drained, well aerated and rich organic matter soil, pH 5.5 - 6.7 (Morton, 1987), while water logging of soils often results in the death of tress within 3-4 days (Storey, 1985). Plants which are used for medicinal purposes are generally cheap and are best sources of pharmacologically active substances and are good resistance to bacterial activity (Basile et al., 1999). In general medicinal purposes, the plant is used tremendously. Whole C. papaya i.e. its fruits, seeds, bark and leaves are used for treatment and curing many disease. Much work and literature have been published related to papaya fruits and seeds. The edible portion of the fruit of $C$. papaya (pawpaw) contains both macro and micro minerals like $\mathrm{Na}, \mathrm{K}, \mathrm{Ca}, \mathrm{Mg}, \mathrm{Fe}, \mathrm{Cu}, \mathrm{Zn}$ and $\mathrm{Mn}(\mathrm{OECD}, 2010)$. The plant is a source of carotenoides, vitamin $\mathrm{C}$, thiamine, riboflavin, niacin, vitamin $\mathrm{B} 6$ and vitamin $\mathrm{K}$ (Bari et al., 2006; Adetuyi et al., 2008 and USDA, 2009). The seed had recently been linked 
to cure sickle cell diseases (Imaga, et al., 2009), poisoning related renal disorder (Olagunju, et al., 2009) and as an anti-helminthes (Okeniyi, et al., 2007).

Leaves contain large amounts of alkaloids, carpaine and pseudocarpine which creates positive effects on heart as well as on respiration (Perry and Metzger, 1980). Leaf extract of C. papaya is well known as an anti-tumor agent (Walter Last, 2008). The papaya fruit, as well as all other parts of the plant, contain a milky juice in which an active principle known as papain is present. Aside from its value as a remedy in dyspepsia and kindred ailments, it has been utilized for the clarification of beer (Ayoola \& Adeyeye, 2010).

The leaves of papaya have been shown to contain many active components that can increase the total antioxidant power in blood and reduce lipid peroxidation level, such as papain, chymopapain, cystatin, tocopherol, ascorbic acid, flavonoids, cyanogenic glucosides and glucosinolates (Noriko Otsuki et. al., 2010)

Reports on different parts of C. papaya have been published, but still a comparative study is to be needed to study the difference in medicinal values of different parts of this plant growing in normal conditions and the C.papaya growing in semi-arid region like Kachchh region. Here the attempt has been done to study the mineral constituents of leaves of $\mathrm{C}$. papaya.

The objective of the study was to identify quantitatively the biochemical constitutions in the leaf of $C$. papaya growing in semi-arid region of Gujarat. Kachchh region in Gujarat is considered to be one of the most arid to semi-arid region in the state as it has greater and little Rann of Kachchh. As reported earlier that C. papaya is well known ethnomedicinal plant used for curing various types of diseases, here the local people also uses papaya as medicine.

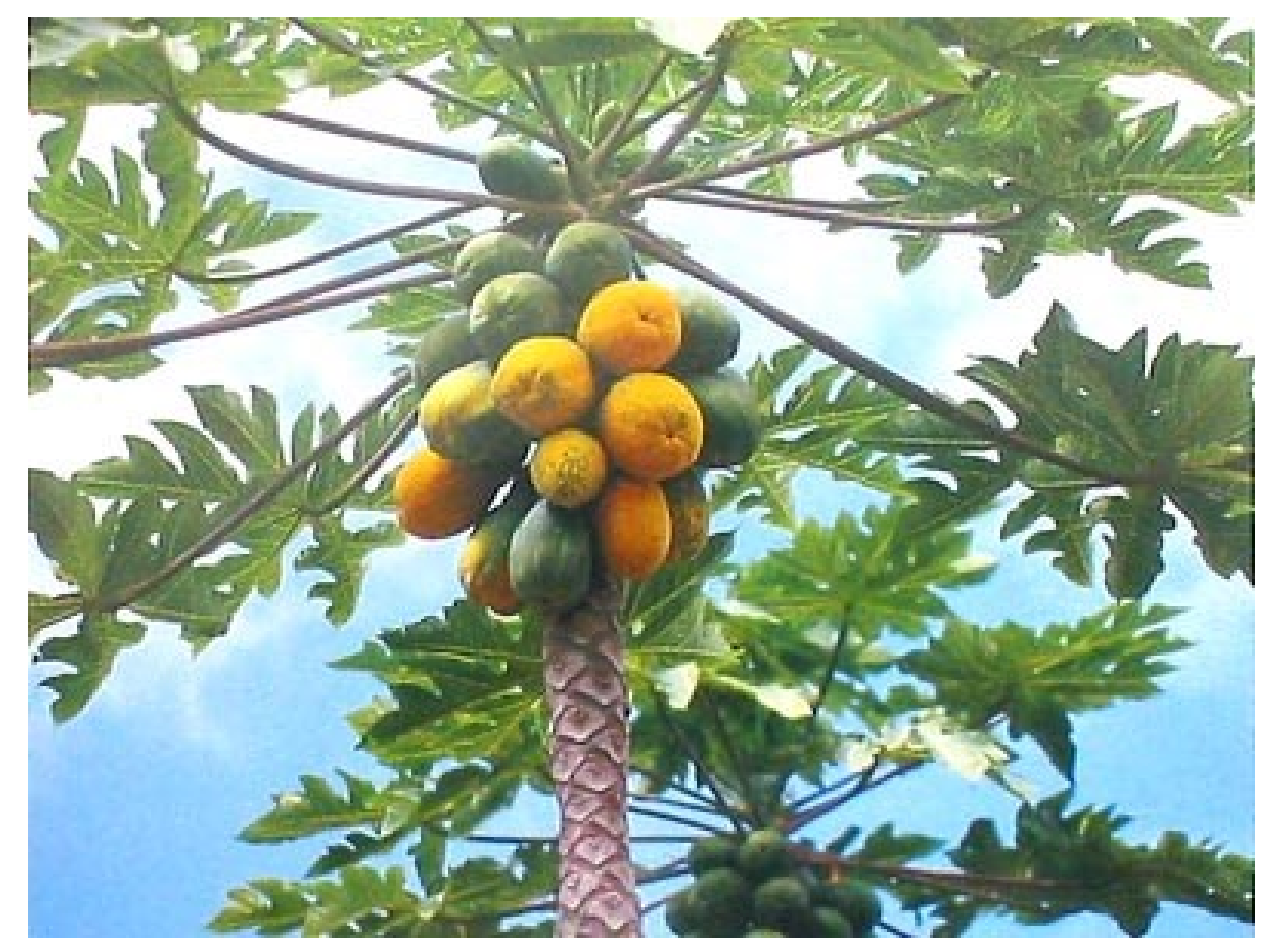

Photo 1. Carica papaya. 


\section{REVIEW OF LITERATURE}

India has rich medical heritage with a large number of traditional practices, systems and medicines as a part of its total health care scenario, some of them are more than 3,000 years old. In spite of remarkable achievements of modern medicines and research, these ancient systems continue to play a major role in the control or alleviation of diseases. In India several scientists have reported the therapeutic importance of the chemical constituents of plants used in ancient Indian medical system. Mutalic G. (1972) has emphasized for research in traditional medicine. In spite of the concurrent use of the extract of Carica papaya with prescription oral hypoglycemic agents in some patients there is a dearth of literature on the effects of the extract on activity of oral hypoglycaemic agents (Fakeye, T.O. et al., 2007 and Oyelola O., 2005). It has been reported by Parle Milind et.al. (2011) that whole papaya plant is useful in various medicinal properties like uterotonic, nephroprotective, anti-inflamatory, anti-tumor, etc. there are several medicinal importance of the whole plant Papaya also has several industrial uses. Biochemically, its leaves and fruit are complex, producing several proteins and alkaloids with important pharmaceutical and industrial applications (El Moussaoui et al. 2001).

Papaya plants are also produced for papain and chymopapain, two industrially important proteolytic enzymes found in the milky white latex exuded by fruits. In general, female fruits tend to exude more papain than hermaphrodite fruits (Madrigal et al. 1980).

\section{MATERIALS AND METHODS}

The leaves of C. papaya were collected from semi-arid region and sun dried for further analysis. The methodology used for different parameters are described below:

Moisture content in leaf: Dried leaves of Carica Papaya sample was weighed into a previously dried and weighed ceramic crucible and dried in a thermostatically controlled oven at $105{ }^{\circ} \mathrm{C}$. The moisture content was then determined by difference and expressed as a percentage of the initial weight of the sample (AOAC, 1990).

Ash content in leaf: Carica Papaya leaf sample was weighed into a previously washed, dried, ignited and weighed Gouch porcelain crucible and then the dish with its contents placed in a Muffle furnace (Gallenkamp, England) preheated to $400{ }^{\circ} \mathrm{C}$ for two hours (2 hrs). The crucibles and their contents were removed and cooled in a desiccator after which they were weighed.

Extraction of Inorganic ions from leaf: Plant material was ignited to give ash at around 450 ${ }^{\circ} \mathrm{C}$ in muffle furnance. After cooling $3 \mathrm{ml}$ of conc. $\mathrm{HCl}$ and $5 \mathrm{ml}$ of water was added. It was cooled and $2 \mathrm{ml}$ of $2.5 \mathrm{~N}$ of $\mathrm{HCl}$ and $10 \mathrm{ml}$ of distilled water was added. It was boiled again and $5 \mathrm{ml}$ of $\mathrm{BaCl}_{2}$ solution was added. Precipitate was washed and the filtrate was diluted to $100 \mathrm{ml}$ with water. i) Sodium, Potassium, Calcium and Lithium was analyzed by Flame Photometer ii) Chloride: Argentometric method iii) Total Hardness (Calcium \& Magnesium hardness): titration method iv) Fluoride: Spectrophotometer method. Reagents used were: a) Alizarin red solution b) Zirconyl acid solution c) Standard fluoride solutions v)Nitrate: Spectrophotometer method. Reagents: a) Phenol disulphonic acid b); Potassium hydroxide solution $(12 \mathrm{~N})$; c) Standard nitrate solution. 


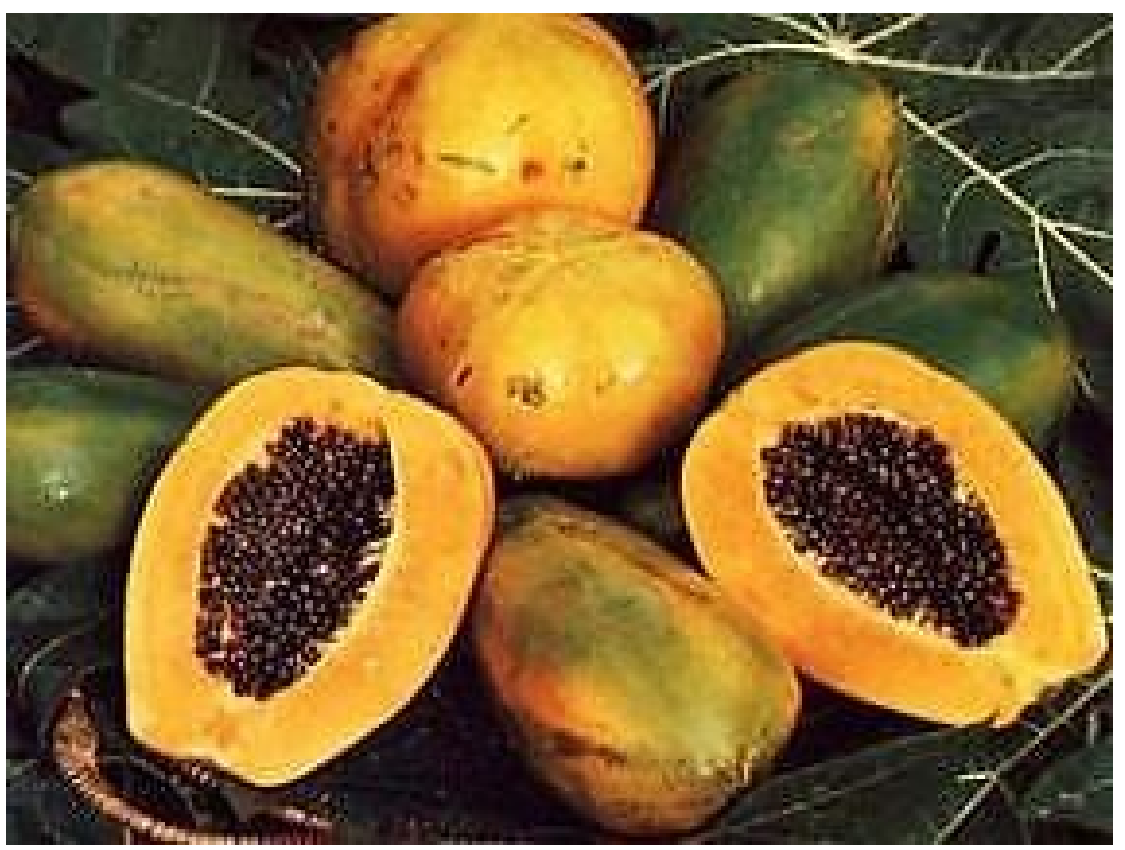

Photo 2. Fruit and seeds of the Carica papaya.

\section{RESULTS AND DISCUSSION}

The leaves of C. papaya were analyzed for study of mineral composition. Samples were collected from semi-arid region of Kachchh district of Gujarat state during the month of January in 2012. Moisture content in the leaves was found to be $8 \%$. The results of moisture content in this region i.e. the samples collected from the semi-arid region were contrary to $81.27 \%$ to $85.17 \%$ in different morphotypes of papaya leaves by Godson E. Nwofia et. al. (2012). While the ash content in leaves was found to be $10 \%$ which was found to be more than the range $1.43 \%$ to $2.25 \%$ as reported by E. Nwofia et. al. (2012).

Calcium and magnesium content plays vital role in different physiological process of plant, the results of calcium and magnesium in leaves of $C$. papaya was found to be 0.31 meq. $\mathrm{gm}^{-1}$ d.wt. and $0.538 \mathrm{meq} \cdot \mathrm{gm}^{-1}$ d.wt., respectively. Lithium in leaves of C. papaya was also noted to be higher $\left(51.86 \mathrm{meq} \cdot \mathrm{gm}^{-1} \mathrm{~d}\right.$.wt.) in amount compared to other mineral ions. Amount of Potassium ion in leaves growing in this region was noted to be $0.574 \mathrm{meq} \cdot \mathrm{gm}^{-1}$ d.wt. Chloride ion concentration was observed to be $0.239 \mathrm{meq} \cdot \mathrm{gm}^{-1}$ d.wt. in C. papaya leaves. Jaime A. Teixeira da Silva et.al. (2007) reported appropriate values in ripen fruit of $C$. papaya.

\section{CONCLUSIONS}

The study of the carica papaya leaves of semi arid zone of kutch region showed that it is rich in elements like $\mathrm{Ca}^{2+}, \mathrm{Mg}^{2+}, \mathrm{Na}^{+}, \mathrm{K}^{+}, \mathrm{Cl}^{-}$and $\mathrm{Li}^{+}$with comparison to other reported analysis of other regions. This shows that the leaves of this region are full of essential elements and can be studied in detail for better ethnomedical uses with compared to the plants of other region. This encourages to study the plant more specifically for many diseases and to elaborate other parts of the plant of this particular region. 


\section{References}

[1] Basile A., Giordano S., Lopez-Saez J. A., Cobianchi R. C., Phytochemistry 52 (1999) 1479-1482.

[2] Fakeye T. O., Abu T., Adebisi O., J Herbal Pharmacotherapy 7(3-4) (2008) 213-227.

[3] Imaga N. O. A., et al., Afric. J. Biochem. Res. 3 (2009) 102-106.

[4] Madrigal L. S., Ortiz A. N., Cooke R. D., Fernandez R. H., Journal of the Science of Food and Agriculture 31 (1980) 279-285.

[5] Morton J. F., Papaya. In: Morton JF (Ed) Fruits of Warm Climates, Creative Resource Systems, Inc., Miami, FL, 1987, pp. 336-346

[6] Mutalik G. S., Research Needs and Traditional Medicine in South East Asia Region Background paper No. SEA/RPD/Tradmed/RSG Meet 1/2, WHO office, N. Delhi 1972.

[7] Moussaoui A. El., et al., Cellular and Molecular Life Sciences 58(4) (2001) 556-570.

[8] P. B. Ayoola, A. Adeyeye, IJRRAS 5(3) (2010 325-328.

[9] Perry L. M., J. Metzger, (1980). Medicinal Plants of East and Southeast Asia: Attributed Properties and Uses. Cambridge: The MIT Press.

[10] OECD 2010. Consensus document compositional consideration for new varieties of papaya (Carica papaya): key food and feed nutrients, anti-nutrients, antitoxicant and allergence. www.eocd.org/biotrack.

[11] Olagunju J. A., et al., Biol. Med. 1 (2009) 11-19.

[12] Okeniyi J. A. O., Ogunlesi T. A., Oyelami O. A., Adeyemi L. A., J. Med. Fd. 10 (2007) 194-196.

[13] Oyelola O., (2005): Evaluation of the hypoglycemic activity of Treculia Africana Decne (root) in normal and diabetic rats. M. Pharm (Clinical Pharmacy) Dissertation University of Ibadan Nigeria.

[14] Storey W. B., (1985). Carica papaya. In: Halevy AH (Ed) CRC Handbook of Flowering (Vol II), CRC Press Inc., Boca Raton, Florida.

[15] O. A. Davies, E. Jaja, International Letters of Natural Sciences 4 (2013) 10-25.

[16] Walter Last (2008). Cancer remedies.

www.health-science-spirit.com/cancer6-remedies. 